Case Report

\title{
Pulmonary Hemorrhage Secondary to Disseminated Strongyloidiasis in a Patient with Systemic Lupus Erythematosus
}

\author{
Erika P. Plata-Menchaca, ${ }^{1}$ V. M. De la Puente-Diaz de Leon, ${ }^{1}$ \\ Adriana G. Peña-Romero, ${ }^{2}$ and Eduardo Rivero-Sigarroa ${ }^{1}$ \\ ${ }^{1}$ Department of Critical Care Medicine, Instituto Nacional de Ciencias Médicas y Nutrición Salvador Zubirán (INCMNSZ), \\ 14000 Mexico City, DF, Mexico \\ ${ }^{2}$ Department of Dermatology, Instituto Nacional de Ciencias Médicas y Nutrición Salvador Zubirán (INCMNSZ), \\ 14000 Mexico City, DF, Mexico
}

Correspondence should be addressed to V. M. De la Puente-Diaz de Leon; vic_puente@yahoo.com.mx

Received 20 April 2015; Accepted 13 May 2015

Academic Editor: Gil Klinger

Copyright (C) 2015 Erika P. Plata-Menchaca et al. This is an open access article distributed under the Creative Commons Attribution License, which permits unrestricted use, distribution, and reproduction in any medium, provided the original work is properly cited.

Introduction. Pulmonary hemorrhage secondary to disseminated strongyloidiasis is an unusual, well-recognized entity in immunocompromised patients with autoimmune disease, which is associated with the hyperinfection syndrome, sepsis, and a high mortality rate. Case Presentation. We present a case of a 44-year-old Mexican woman with systemic lupus erythematosus and acute bacterial meningitis who developed pulmonary hemorrhage with acute respiratory failure requiring mechanical ventilation, treated with broad spectrum systemic antibiotics and high dose methylprednisolone, who subsequently developed a characteristic purpuric skin eruption and septic shock and died two days later of refractory hypoxemia caused by massive pulmonary bleeding. The postmortem examination reports filariform larvae of S. stercolaris in lung, skin, and other organs. Conclusion. This case highlights the importance of considering disseminated strongyloidiasis in the differential diagnosis of diffuse alveolar hemorrhage in systemic lupus erythematosus, and screening for $S$. stercolaris infection before initiation of immunosuppressive therapy should be considered, especially in endemic areas. Disseminated strongyloidiasis has a high mortality rate, explained in part by absence of clinical suspicion.

\section{Introduction}

Disseminated strongyloidiasis (DS) is the systemic infection in immunocompromised hosts of Strongyloides stercoralis, a parasite that commonly causes limited gastrointestinal disease in immunocompetent hosts. S. stercoralis is a widespread, soil-transmitted intestinal nematode common in tropical and subtropical areas affecting the lower socioeconomic groups [1]. Risk factors associated with DS are those that affect cellular immunity, such as hematologic malignances, HTLV-1 infection, bone marrow transplantation, anti-TNF medication, HIV, and glucocorticoids [2]. The latter associated with impairment of the intestinal wall thickness, concomitant bacterial translocation, and provoking superinfection syndrome, which refers to the widespread dissemination of the parasites from the gut to diverse organs [3]. Approximately $30 \%$ of cases of DS have been reported in immunocompromised patients with autoimmune disease. The diagnosis is usually made in concentrated repeated stool examinations; serial testing is recommended to increase the sensitivity of the diagnostic test [4], although the serological testing by the ELISA method is the best option for this purpose [5].

\section{Case Presentation}

A 44-year-old woman, from Veracruz, Mexico, of low socioeconomic income, was admitted to the hospital with one-week history of progressive headache, phonophobia, high-grade fever, vomiting, and watery diarrhea. She had systemic lupus erythematosus (SLE) since 2003, with cutaneous, joint, and renal involvement. In the previous month, SLE-associated thrombotic thrombocytopenic purpura (TTP) was diagnosed 


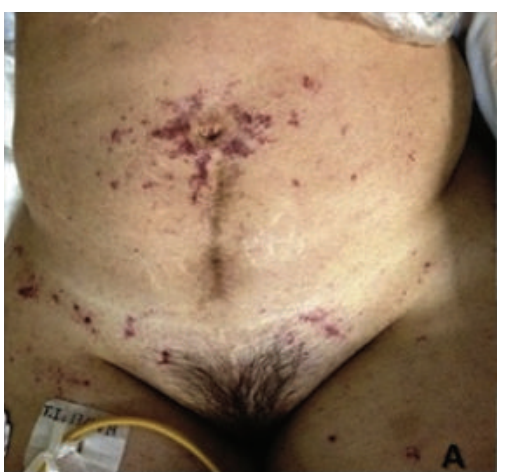

(a)

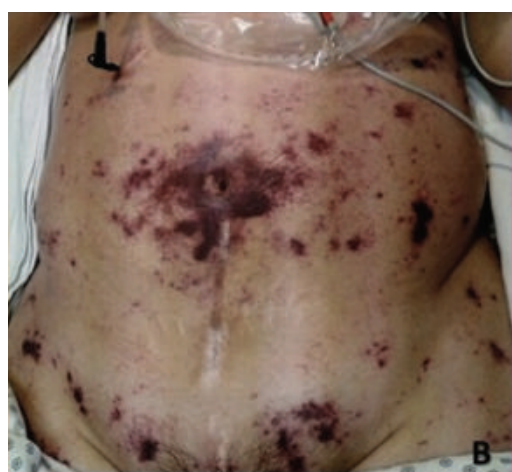

(b)

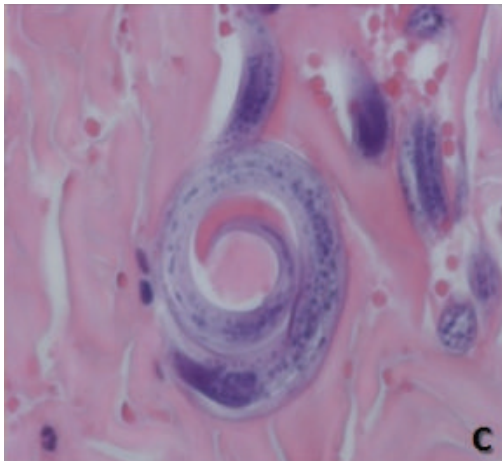

(c)

Figure 1: Purpuric dermatosis and skin biopsy. Punctiform periumbilical purpuric macules (a). 24 hours later, dermatosis worsened and was confluent with persistence of periumbilical involvement ("Thumb print sign") (b). Filariform larvae were observed in the dermis (c).

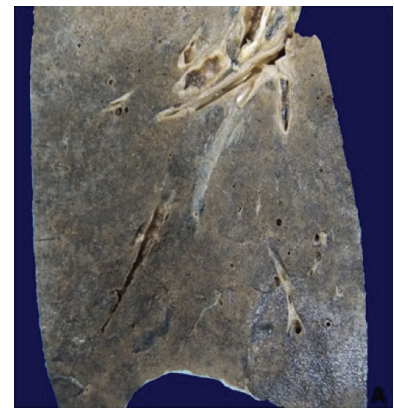

(a)

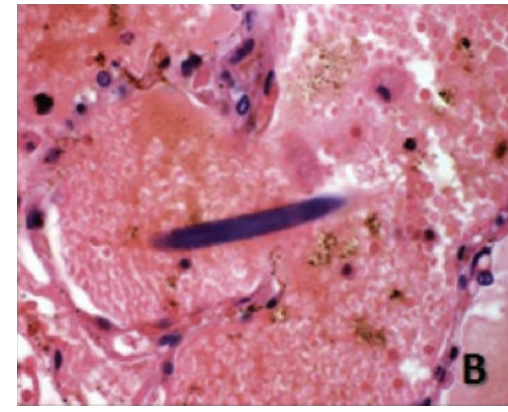

(b)

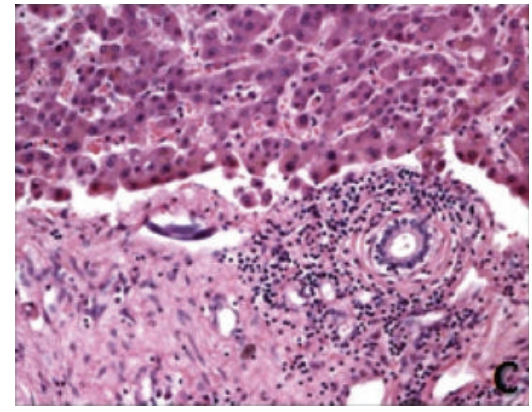

(c)

FIgURE 2: Postmortem examination. Macroscopic appearance of lung (a). S. stercoralis filariform larvae in lung (b) and liver (c).

and was treated with plasmapheresis, cyclophosphamide, and $1 \mathrm{mg} / \mathrm{kg} /$ day of prednisone.

At admission, she had systemic inflammatory response syndrome and nuchal rigidity; focal neurologic signs and clinical signs of lupus activity were absent. Laboratory evaluation showed $\mathrm{Hb} 11.2 \mathrm{gr} / \mathrm{dL}$, MCV $103 \mathrm{fL}$, eosinophil count $150 \mathrm{cel} / \mathrm{mm}^{3}$, serum creatinine $0.8 \mathrm{mg} / \mathrm{dL}$, haptoglobins $77 \mathrm{mg} / \mathrm{dL}(>30 \mathrm{mg} / \mathrm{dL})$, ALT $59 \mathrm{UI} / \mathrm{L}(<34)$, AST $78 \mathrm{UI} / \mathrm{L}$ (<40), LDH $310(<270 \mathrm{mg} / \mathrm{dL})$, cobalamin levels $406 \mathrm{pg} / \mathrm{mL}$ ( $>150 \mathrm{pg} / \mathrm{mL}$ ), folates $49.6 \mathrm{ng} / \mathrm{mL}(>4 \mathrm{ng} / \mathrm{mL})$, C3 $96.5 \mathrm{mg} / \mathrm{dL}$ $(87-200 \mathrm{mg} / \mathrm{dL})$, lactate $0.9(<2.2 \mathrm{mmol} / \mathrm{L})$, and mild proteinuria $(310 \mathrm{mg} /$ day). The initial chest X-ray and headCT did not show any abnormalities. The lumbar puncture revealed $\mathrm{pH} 7.35$, glucose $45 \mathrm{mg} / \mathrm{dL}$ (serum glucose $130 \mathrm{mg} / \mathrm{dL}$ ), proteins $329 \mathrm{mg} / \mathrm{dL}$, 42 white blood cells $/ \mathrm{mm}^{3}$ (95\% neutrophils), and 2 red blood cells $/ \mathrm{mm}^{3}$. Enterococcus gallinarum was isolated in cerebrospinal fluid and intravenous ampicillin was administrated with improvement in the neurological symptoms. On day 3 , she developed hemoptysis with bilateral patchy pulmonary infiltrates on chest X-ray, a drop in hemoglobin concentration, and acute respiratory failure, which needed mechanical ventilation and admission to the intensive care unit (ICU). We obtained cultures and started methylprednisolone boluses and broad spectrum antibiotics. The initial clinical diagnosis was diffuse alveolar hemorrhage caused by SLE activity without sufficient clinical criteria of nosocomial pneumonia. On day 4 she developed a purpuric skin rash and a biopsy was performed (Figure 1). The additional approach did not show any evidence of hemolysis, disseminated intravascular coagulation, nor TTP. One day later she had clinical deterioration with septic shock and progression of the radiographic infiltrates. On day 6 she died because of refractory hypoxemia secondary to massive pulmonary bleeding. Filariform larvae of S. stercoralis were observed in the skin biopsy and postmortem examination report was SLE and DS with lung, thyroid, liver, gut, and skin involvement (Figure 2).

\section{Discussion}

Common presenting symptoms of acute disseminated strongyloidiasis in immunocompromised hosts include fever, abdominal pain, diarrhea, neurologic involvement, skin lesions, myositis, acute respiratory failure, and sepsis. The pathognomonic rash of Strongyloides infection is serpiginous and urticarial "larva currens" $[5,6]$. Rarely, in $\mathrm{DE}$, a progressive petechial purpuric eruption over the abdominal and proximal thigh, the "thumbprint purpura" (Figure 1) [7], is observed in absence of eosinophilia [8].

Evidence of superimposed bacterial infections that complicate the clinical course of patients, such as Pseudomonas aeruginosa and Acinetobacter pneumonia and Enterococcus 
faecalis meningitis, has been described [8,9] which often progress to septic shock and are the direct cause of death in $80 \%$ of cases.

Differential diagnosis of DS includes SLE flare, vasculitis, inflammatory bowel disease [10], other systemic infections, and drug reactions. Treatment of DS has been done with ivermectin and albendazole, showing cure rate for immunocompromised patients of approximately 60\%-70\% [11-13].

The most common cause of diffuse alveolar hemorrhage in SLE is pulmonary capillaritis, often associated with bacterial pneumonia. The mortality rate has been declined since the rapid recognition and beginning of aggressive treatment with high dose methylprednisolone and cyclophosphamide. Because immunosuppressive therapy may provoke superinfection syndrome, screening for $S$. stercoralis infection before initiation of immunosuppressive therapy should be considered, especially in endemic areas [5-9].

\section{Conclusion}

Pulmonary hemorrhage secondary to DS is an unusual, wellrecognized entity in immunocompromised patients that is associated with a high mortality rate, explained by disease severity and absence of clinical suspicion. It should be considered in the differential diagnosis of pulmonary hemorrhage in a patient with SLE before initiating steroids and especially when the clinical status worsens rapidly with steroids.

\section{Consent}

Written informed consent was obtained from the patient for publication of this case report and accompanying images.

\section{Conflict of Interests}

The authors declare that they have no competing interests.

\section{Authors' Contribution}

Erika P. Plata-Menchaca and V. M. De la Puente-Diaz de Leon analyzed and interpreted the patient data and were the major contributors in writing the paper. V. M. De la Puente-Diaz de Leon, Adriana G. Peña-Romero, and Eduardo RiveroSigarroa analyzed and interpreted the patient data. All authors read and approved the final paper.

\section{Acknowledgments}

The authors wish to thank Martínez Braulio M.D., Consuelo Rodríguez M.D., Niembro Dolores M.D., Galindo Arturo M.D., and Ponce de León Alfredo M.D.

\section{References}

[1] P. B. Keiser and T. B. Nutman, "Strongyloides stercoralis in the immunocompromised population," Clinical Microbiology Reviews, vol. 17, no. 1, pp. 208-217, 2004.
[2] C. G. Wambier, F. B. M. Lemos, M. A. Cappel, F. BellissimoRodrigues, and N. T. Foss, "Generalized serpiginous eruption during immunosuppressive treatment for leprosy reactive neuritis," PLoS Neglected Tropical Diseases, vol. 5, no. 12, Article ID e1357, 2011.

[3] M. N. Ly, S. L. Bethel, A. S. Usmani, and D. R. Lambert, "Cutaneous Strongyloides stercoralis infection: an unusual presentation," Journal of the American Academy of Dermatology, vol. 49, no. 2, pp. S157-S160, 2003.

[4] Y. Sato, J. Kobayashi, H. Toma, and Y. Shiroma, "Efficacy of stool examination for detection of Strongyloides infection," The American Journal of Tropical Medicine and Hygiene, vol. 53, no. 3, pp. 248-250, 1995.

[5] T. L. Meinking, C. N. Burkhart, and C. G. Burkhart, "Changing paradigms in parasitic infections: common dermatological helminthic infections and cutaneous myiasis," Clinics in Dermatology, vol. 21, no. 5, pp. 407-416, 2003.

[6] S. L. Mackey and K. F. Wagner, "Dermatologic manifestations of parasitic diseases," Infectious Disease Clinics of North America, vol. 8, no. 3, pp. 713-743, 1994.

[7] R. S. Purvis, E. L. Beightler, D. G. Diven, R. L. Sanchez, and S. K. Tyring, "Strongyloides stercoralis hyperinfection," International Journal of Dermatology, vol. 31, no. 3, pp. 160-164, 1992.

[8] J. I. F. Salluh, F. A. Bozza, T. S. Pinto, L. Toscano, P. F. Weller, and M. Soares, "Cutaneous periumbilical purpura in disseminated strongyloidiasis in cancer patients: a pathognomonic feature of potentially lethal disease?" Brazilian Journal of Infectious Diseases, vol. 9, no. 5, pp. 419-424, 2005.

[9] C. S. Lam, M. K. H. Tong, K. M. Chan, and Y. P. Siu, "Disseminated strongyloidiasis: a retrospective study of clinical course and outcome," European Journal of Clinical Microbiology and Infectious Diseases, vol. 25, no. 1, pp. 14-18, 2006.

[10] G. M. Hayden and S. A. Atlas, "Strongyloidiasis masquerading as inflammatory bowel disease in a patient with lupus erythematosis: a case report," Connecticut Medicine, vol. 59, no. 11, pp. 649-650, 1995.

[11] K.-D. Lessnau, S. Can, and W. Talavera, "Disseminated Strongyloides stercoralis in human immunodeficiency virus-infected patients: treatment failure and a review of the literature," Chest, vol. 104, no. 1, pp. 119-122, 1993.

[12] N. C. Iriemenam, A. O. Sanyaolu, W. A. Oyibo, and A. F. Fagbenro-Beyioku, "Strongyloides stercoralis and the immune response," Parasitology International, vol. 59, no. 1, pp. 9-14, 2010.

[13] R. Toledo, C. Muñoz-Antoli, and J. G. Esteban, "Strongyloidiasis with emphasis on human infections and its different clinical forms," Advances in Parasitology, vol. 88, pp. 165-241, 2015. 


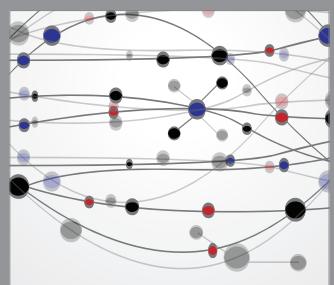

The Scientific World Journal
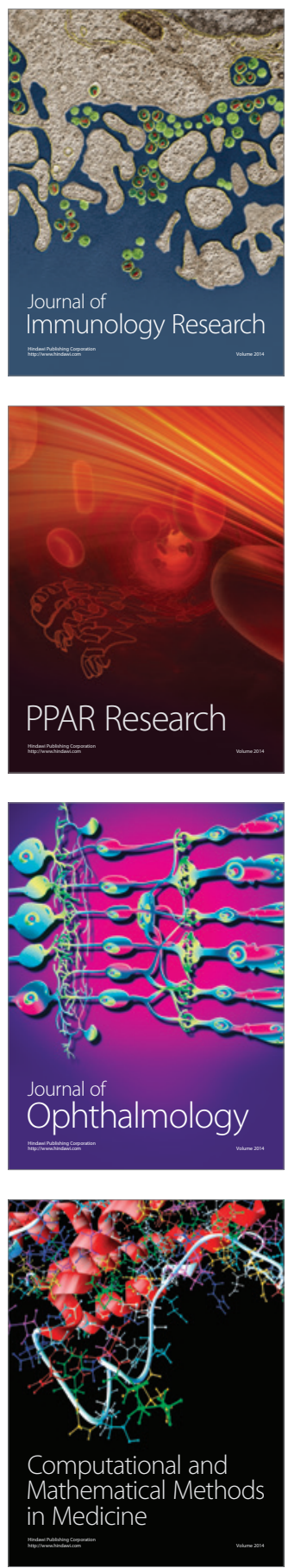

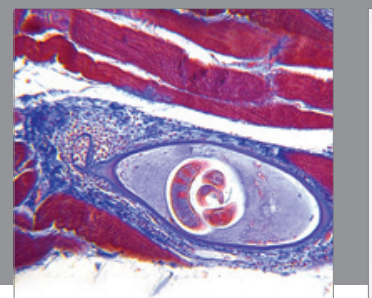

Gastroenterology

Research and Practice
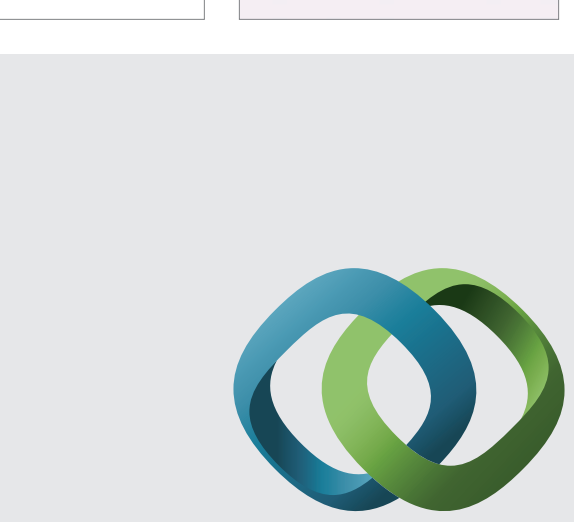

\section{Hindawi}

Submit your manuscripts at

http://www.hindawi.com
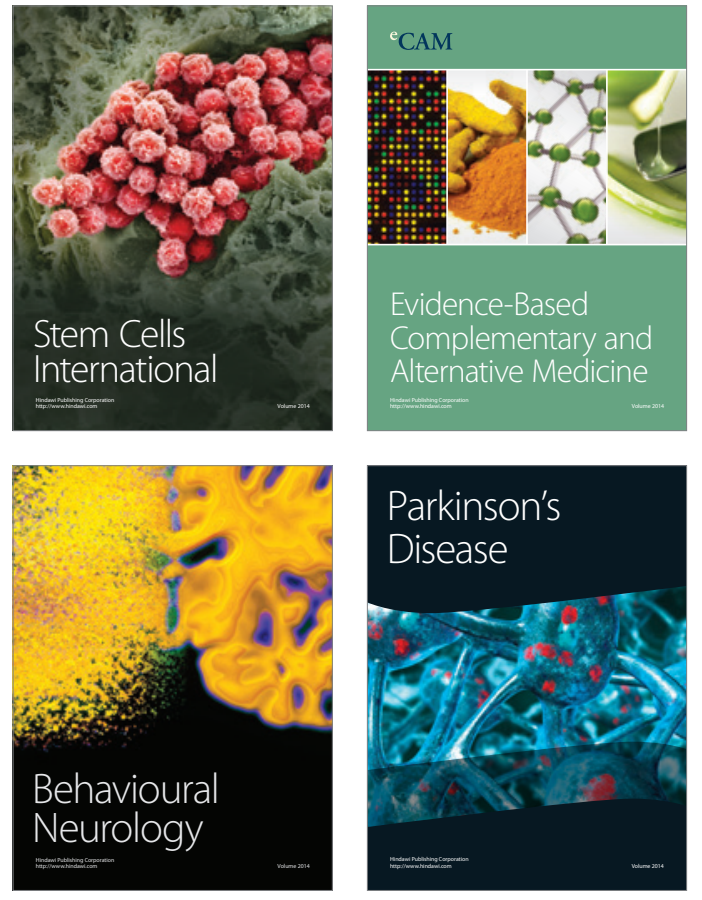
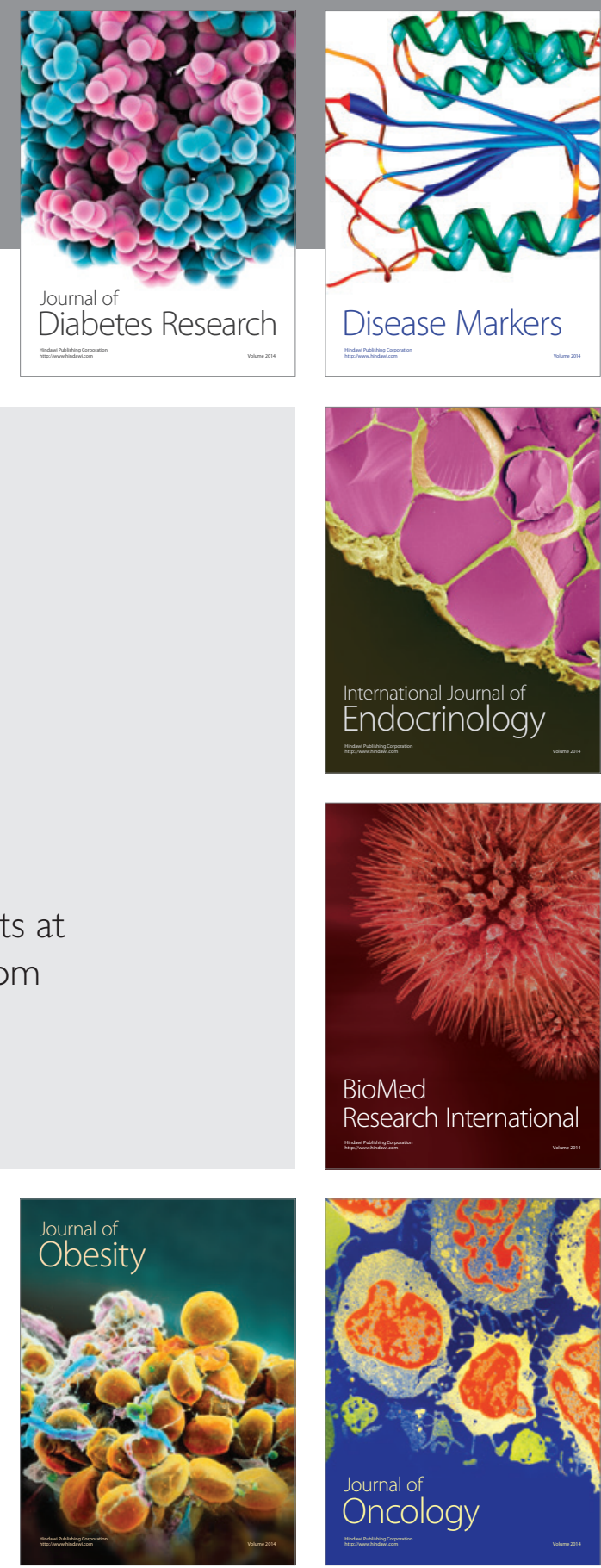

Disease Markers
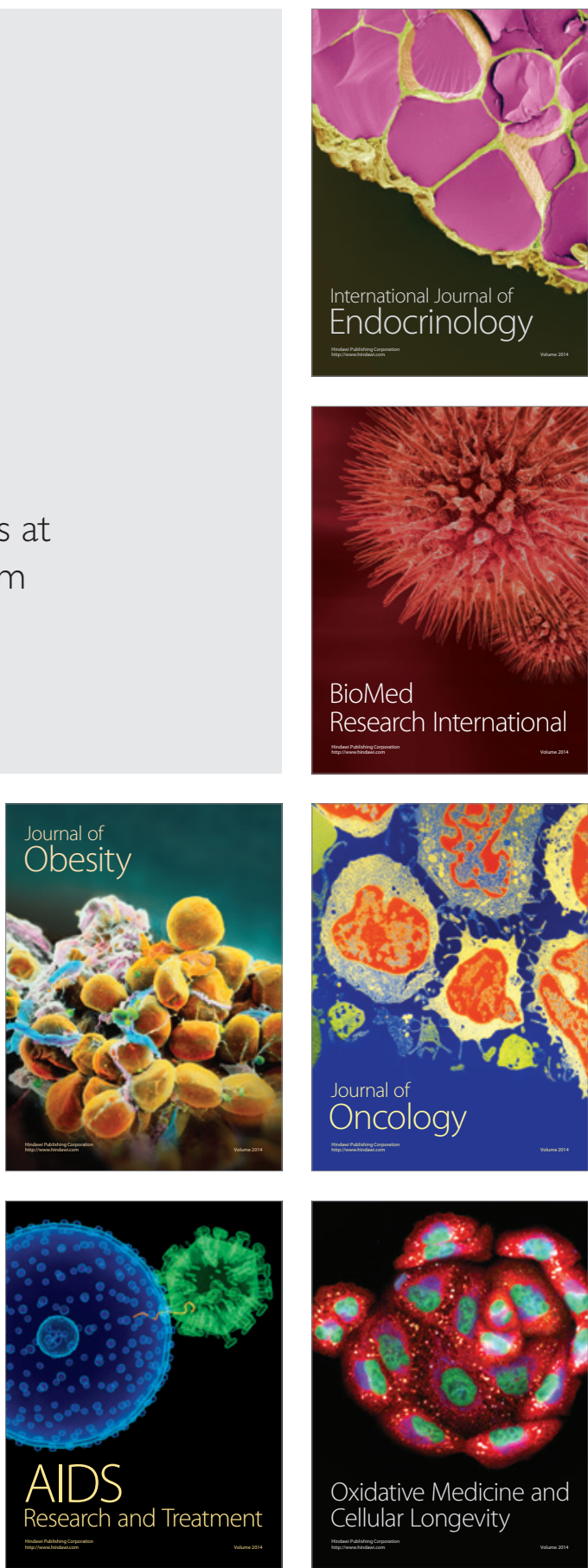